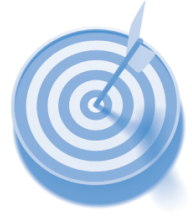

Joanne Boniface,

David Read* and

Andrea E Russell

School of Chemistry

University of Southampton

Highfield

Southampton

So17 1BJ

*d.read@soton.ac.uk

This work is part of an on-going initiative which aims to identify effective methods to support students in becoming independent learners when making the transition to university...

\section{Sharing learning outcomes in chemistry teaching at HE level: beneficial or detrimental?}

\begin{abstract}
The sharing of explicit learning objectives and/or learning outcomes is considered to be good practice in schools, with OFSTED observation criteria indicating that this is a pre-requisite to a good or outstanding lesson ${ }^{1}$. Such practice does not appear to be widespread in chemistry teaching at HE level. Whilst a statement of aims/objectives/ outcomes can normally be found in the documentation accompanying any given unit of teaching, these are typically in a less student-friendly format than those used in school, or are too vague to be useful. At the same time, many lecturers do communicate aims at the start of a lecture, but there may be scope for doing this in a more effective way. The extent to which students are exposed to 'learning outcomes' varies greatly from institution to institution, discipline to discipline and from teacher to teacher, and as such it is difficult to discern the best approach.
\end{abstract}

This article presents some background on developments at pre-university level that have influenced practice in this area, and outlines the findings of a research project carried out in the School of Chemistry at the University of Southampton. The project probed the views of staff and students regarding the usefulness of learning outcomes. Several different approaches to sharing learning outcomes with first year students were trialled and evaluated during the course of the 2010-11 academic year. This work is part of an on-going initiative which aims to identify effective methods to support students in becoming independent learners when making the transition to university, and to improve retention rates.

\section{Background}

Learning outcomes are specific, concise statements describing precisely what students are expected to be able to do at the end of any learning activity. Watson succinctly defined a learning outcome as 'something that students can do now that they could not do previously... as a result of a learning experience'2. Guidance regarding the use of learning outcomes at HE level has been provided by Overton ${ }^{3}$, who noted that they should:

- be written in the future tense

- identify important learning requirements

- be achievable and assessable

- use clear language easily understandable to students

It is worth noting that there is some scepticism among practitioners regarding the true value of learning outcomes, and particularly the additional bureaucracy entailed ${ }^{4}$, and these reflect the concerns expressed by some staff at HE level. As such, there is clearly value in carrying out research in this area to ascertain the value that students place on learning outcomes, and to find out how they are used in self-study.

The investigation into the value of sharing learning outcomes with students was carried out by a BSc student as part of a final year research project in chemical education ${ }^{5}$. Learning outcomes were written in a collaborative process between the student and the lecturers using the guidance of Bloom's Taxonomy ${ }^{6,7}$. After receiving staff approval, these were shared with students in different ways in an attempt to identify the most effective approach. Student feedback on the use of learning outcomes was obtained from student interviews and a survey conducted using electronic voting systems. The overall aim of the project was to find out if shared learning outcomes are beneficial to student learning, with the evidence collected then being used in staff discussions regarding the future development of the course. 
In considering the findings described below, it should be noted that, in an ideal world, the writing of learning outcomes should be the first stage in the creation of any unit of teaching. As such, it is acknowledged that the project described herein goes about things in a 'back-to-front' fashion. It should be noted, however, that all staff were very clear in their own minds about what it was that students were meant to learn from a particular lecture and this had always been communicated in the introduction to the lectures and in a summary at the end. An additional aim of the project was to find out if there was a more effective way of communicating this information to students.

\section{Learning outcomes for lectures in semester one}

The semester one taught material formed the basis of an exercise which would probe the views of staff about learning outcomes and would consider a process for sharing them with students in the future. As such, the intention was not to share learning outcomes with students during teaching in semester one. Learning outcomes were compiled into a master document for detailed analysis over the Christmas break. It should be emphasised that this study considered learning outcomes relating to specific lectures, rather than overarching module learning outcomes which are more universal in nature.

Figure 1 shows a list of learning outcomes taken from one organic chemistry lecture which took place in Semester 1. It is interesting to note that there are 10 discreet learning outcomes in this list, which is a significant increase on the 3 or 4 that would typically be covered in an A-level lesson.
After a favourable response from the staff involved, the learning outcomes for all lectures that took place in semester one were made available to students for download from the online Blackboard course on their return to Southampton after Christmas. As teaching had finished before Christmas, students would only be able to use the learning outcomes to support their revision. The students were also informed that an investigation into the effectiveness of sharing learning outcomes was being conducted, and that their views as volunteers would be sought for the evaluation of the project.

\section{Learning outcomes for lectures in semester two}

In order to allow the project student enough time to complete the evaluation process, learning outcomes were only written for a small number of lectures in semester two. One lecturer who was delivering 9 lectures in physical chemistry agreed to take part in this part of the investigation, which looked at different approaches to sharing learning outcomes with students. It was originally intended that three approaches would be taken:

(a) Learning outcomes shared after each block of lectures (there were three blocks of three lectures in this part of the unit).

(b) Learning outcomes shared after each lecture.

(c) Learning outcomes shared before each lecture.

Figure 2 shows the points at which learning outcomes were shared during the sequence of lectures. Due to time constraints, the learning outcomes for both of the first two blocks of three lectures were shared at the end of each block

\section{By the end of this lecture students should be able to...}

Define Huckel's rule (aromatic molecules are cyclic planar molecules that have fully conjugated m-systems and contain $(4 n+2) \pi$-electrons) and explain how benzene obeys this rule.

Draw and explain the structure of benzene including the hybridisation of orbitals and the planar delocalised $\pi$ system.

Describe the high stability of aromatic molecules; activation required for electrophilic aromatic substitution and a catalyst is used during hydrogenation.

Write the mechanism for the addition reaction of bromine to ethene; including the structure of the bromonium ion intermediate.

Recall that for electrophilic aromatic substitution benzene must be activated by a Lewis acid and that the reaction involves the $\pi$ electrons.

Draw all resonance structures to show delocalisation in the intermediate cation formed during electrophilic aromatic substitution.

Explain the role of substituent effects in determining the rate of electrophilic aromatic substitution at the para- position (e.g. in anisole) in terms of activation energy and stabilisation of the transition state by the $\mathrm{MeO}$ - group (+M and $-\mathrm{I}$ effect).

Recall and describe the structure of aromatic heterocyclic compounds; pyridine, pyrrole and furan; all planar with conjugated $\pi$ systems containing 6 electrons.

Compare and explain the basicity of pyrrole and pyridine; pyridine has the lone pair orthogonal to $\pi$ system and protonation destroys aromaticity, pyrrole has its lone pair conjugated into the $\pi$ system.

Describe the acidity of cyclopentadiene; i.e high acidity due to the stable aromatic anion conjugated base so has a low pKa value and is easily deprotonated. 


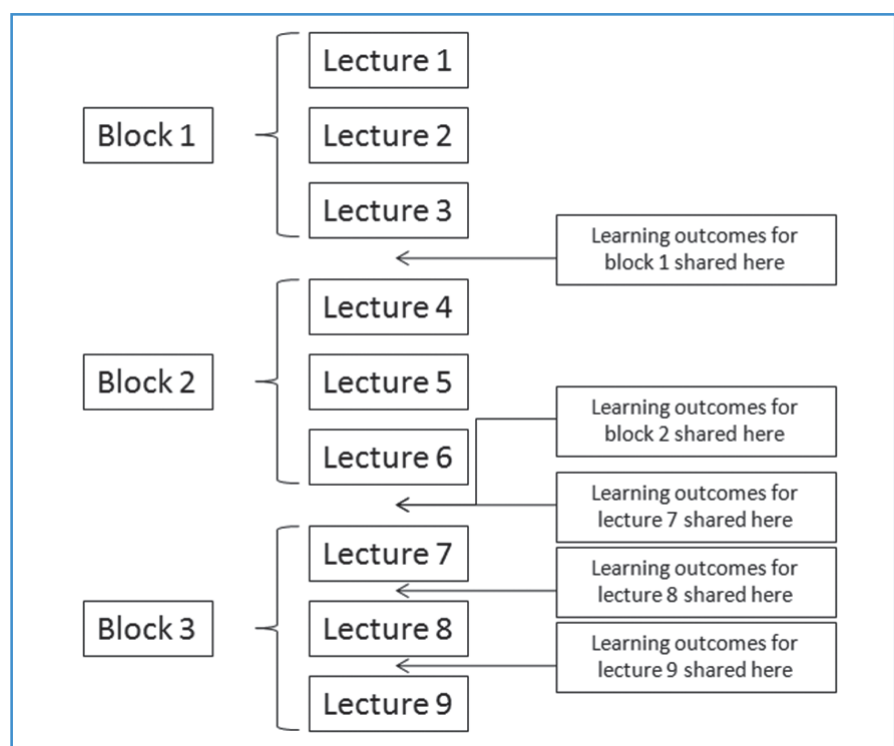

Figure 2: When learning outcomes were shared during the lecture course

(i.e. after lecture three and lecture six). This meant that it was not possible to investigate approach (b), as it was deemed that approach (c) would provide more interesting data and this was used for the lectures in block 3 . In line with this, the learning outcomes for lectures seven, eight and nine were made available after each of the preceding lectures had taken place. In all cases, hard copies were issued during lectures, with material also available in electronic form on Blackboard. Students were kept informed by regular announcements during lectures and by e-mail.

\section{The staff view of learning outcomes}

Although staff were happy at the outset with the idea of a project student writing learning outcomes for their lectures, they had been largely unconvinced about the value of doing so. Some staff felt that a list of explicit learning outcomes was too much like a 'syllabus', which could be seen as 'spoon-feeding' or may actually place a boundary on students' learning. It was therefore interesting to note the very positive response of all the staff on the first occasion that they read a set of learning outcomes for one of their lectures. They were all impressed with the simplicity of the statements which concisely outlined the key learning points for students, while a lengthy list of learning outcomes was reassuring in showing

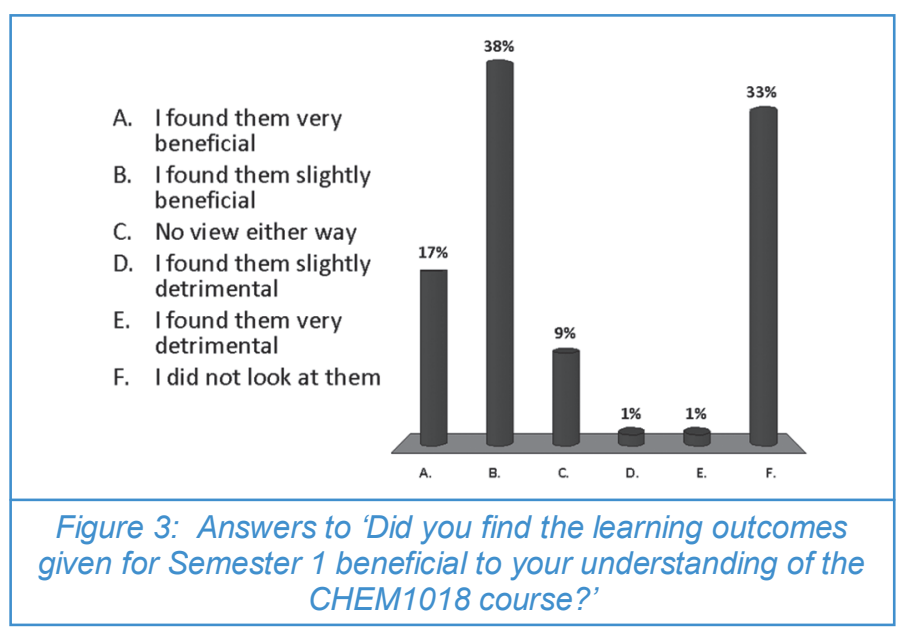

just how much material is covered in a typical lecture. As mentioned previously, all staff consented to making the complete list of learning outcomes available to students for use in their revision, and they all expressed an interest in finding out more about how students would use them and what the benefits might be.

\section{The student response to shared learning outcomes Quantitative evaluation}

At the end of the series of lectures (semester two), a survey of 91 first year students was conducted using electronic voting systems. The data collected showed that two thirds of students had made use of the learning outcomes in some way. The answer to the question posed in the title of this article is indicated in Figure 3, which shows that a large majority of students who had looked at the semester 1 learning outcomes felt that doing so had been beneficial to their understanding. While most students used the learning outcomes individually, 10 students indicated that they had used the learning outcomes in groups, which was seen as a positive result.

Student views regarding the two different approaches to sharing learning outcomes that were trialled in semester two are shown in figures 4 and 5 . It is clear that students were much more likely to interact with the learning outcomes in a meaningful way in their study after lectures rather than beforehand. A small number of students indicated that sharing learning outcomes beforehand could have a detrimental effect, perhaps by giving an impression that there would be no point in going to lectures if the content was already known.
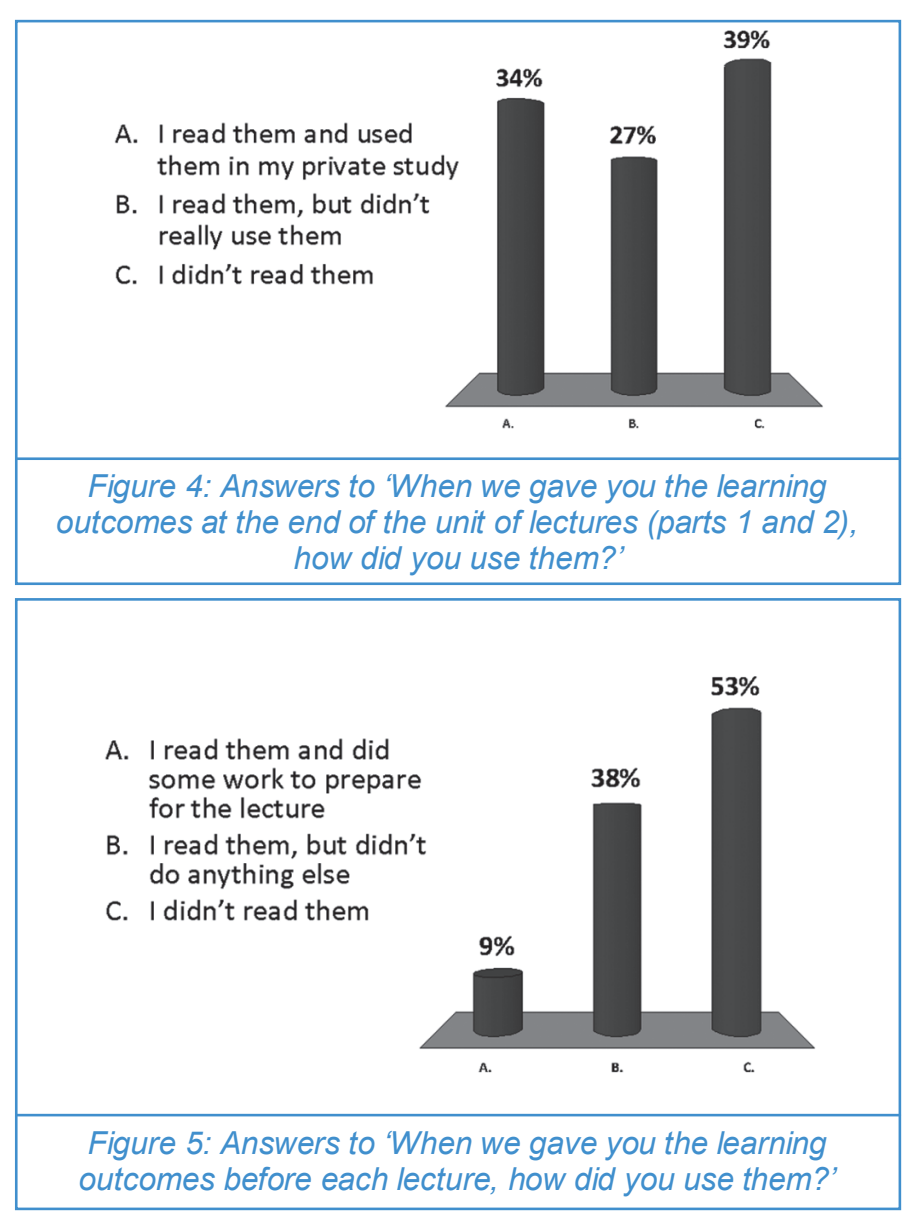
A. Publish learning outcomes before the course only

B. Give learning outcomes before each lecture

C. Give the learning outcomes at the end of the lecture

D. Give the learning outcomes at the end of the week

E. Give learning outcomes after each block of lectures

F. Give learning outcomes at the end of the semester

G. Don't give learning outcomes at all

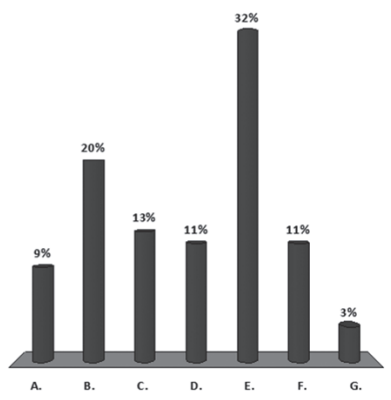

Figure 6: Answers to 'What would be the most effective strategy for learning outcomes?'

Finally, figure 6 shows the students' views on when is the most appropriate time to share the learning outcomes. Although there is a spread of opinions, the most commonly held view was that learning outcomes should be shared at the end of each block of lectures, although a significant number also saw value in them being shared before. Of course, if the latter approach is taken, then the learning outcomes are still available for everyone to use at any point afterwards, and this answer is perhaps more a reflection of when students would be likely to pay attention to the learning outcomes.

\section{Qualitative evaluation}

Six students who had used the semester one learning outcomes during their study were interviewed at the start of semester two. Follow-up interviews were conducted with two of these individuals towards the end of the semester.

One student mentioned that he was "intimidated by the fact that there were so many" learning outcomes, showing that our initial concerns about the sheer number of learning outcomes were justified. However, this student indicated that he had gained confidence by working through the list of learning outcomes with some of his peers, which wasn't necessarily expected. Another student felt that it was useful to see the learning outcomes as this prevented her from "underestimating the amount covered in lectures".

Some students reported using the learning outcomes as a checklist to go through after revising a particular topic, with one describing a 'traffic lighting' system to indicate their confidence level for a particular item, which was beneficial in highlighting key areas to focus on in subsequent study. Another student remarked that it is possible to "get lost with lecture notes and the learning outcomes can guide you through what you really need to know". A further comment was that learning outcomes "clarified points well and having them to look back on to summarise content is excellent".

Some comments were particularly interesting in showing that the learning outcomes were helping students to 'scaffold' their learning, with one noting that the exercise "allowed me to see how all the learning outcomes were connected". Another student expressed that the learning outcomes would be beneficial "by showing how one piece of knowledge, once learnt, would assist me later on in the course". This individual also "linked certain learning outcomes to parts of the textbook for easier learning", showing that shared learning outcomes can support students in their self-study.
As indicated in the previous section, the majority of students did not interact meaningfully with learning outcomes that were shared prior to lectures. The main reason given was that students found that the learning outcomes for material they hadn't seen already were difficult to interpret, meaning they preferred to look at them after the lecture instead.

\section{Conclusions}

The evidence shows that students do see value in shared learning outcomes, with a range of different benefits described. The fact that students reported that looking at learning outcomes after a block of lectures helped them to summarise the key learning and to see how different concepts link together is a very positive result, as these are key independent learning skills that many of our incoming students struggle to come to develop. An additional benefit that hadn't been predicted was the fact that the learning outcomes were used to facilitate peer-assisted learning. The results of this project have also helped to change staff perceptions of learning outcomes, and will lead to changes in the delivery of the first year course at Southampton, showing that such final year projects really can have an impact on teaching at $\mathrm{HE}$ level. ${ }^{5}$

Whether or not detailed learning outcomes should be written and shared for all lectures throughout a degree programme is a question that should be considered carefully. This is certainly beneficial early on, when the sheer volume of material encountered is so much greater than that covered in a typical school lesson. Also, at school, the onus is on the teacher to ensure that students achieve the learning outcomes, while at university, the responsibility moves to the student. Explicit learning outcomes might help students to make the transition to university learning more effectively by clarifying exactly what they are learning. This might help to improve retention rates, with students potentially being less likely to 'take fright' in the early part of their degree studies. There is certainly evidence from the interviews that students took some reassurance from using learning outcomes in their studies.

However, learning outcomes should be used with some caution. One student stated that he liked them because "I didn't waste time learning things that I didn't need to know". This should give pause for thought, as it would be a shame if students were discouraged from reading around their subject and finding topics that they are really interested in, choosing instead to simply learn things that might come up in an exam. Such a situation flies in the face of what 'reading for a degree' is all about, and would rightly be considered to be detrimental to the student learning experience. It may therefore be beneficial to share learning outcomes which are less explicit as students advance through their studies, encouraging them to develop their own interests and take control of their own learning, while also achieving what they need to in order to graduate with the degree they want. 


\title{
References
}

1. The terminology used by OFSTED and those involved in education development does have a tendency to evolve, so care should be taken when reading about the topic. See: Beere, J. (2010) The Perfect (OFSTED) Lesson, Gilbert, I. (Ed.), Crown House Publishing. All guidance regarding the design and delivery of 'Outstanding' lessons emphasises the importance of sharing the learning objectives of any lesson in whatever form is deemed to be appropriate.

2. Watson, P. (2002) The Role and Integration of Learning Outcomes into the Educational Process, Active Learning in Higher Education, 3, 205-219.

3. Overton, T. L. (2005) Writing Learning Outcomes: Advice on defining courses using an outcomes-based approach, Higher Education Academy, UK Physical Sciences Centre.

4. Newman, M. (2008) Inappropriate use of learning outcomes slated, Times Higher Education Supplement, $<w w w . t i m e s h i g h e r e d u c a t i o n . c o . u k / s t o r y . a s p ?$ storyCode $=400576 \&$ sectioncode $=26>$ (accessed on $30^{\text {th }}$ April 2011)

5. Page, E. M., Read. D. and Rowley, N. M. (2011) Sowing the seeds of change: students taking the lead in chemical education research projects, New Directions in the Teaching of Physical Sciences, 7, 69-71.

6. Bloom, B. S. (1956) Taxonomy of Educational Objectives, the classification of educational goals Handbook I: Cognitive Domain. McKay, New York.

7. Other useful background to learning outcomes can be found here:

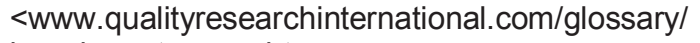
learningoutcomes.htm> (accessed 30th April 2011).

\author{
The fact that students \\ reported that looking at \\ learning outcomes after \\ a block of lectures \\ helped them to \\ summarise the key \\ learning and to see how \\ different concepts link \\ together is a very positive \\ result...
}

